Revista Brasileira de Agricultura Irrigada v.10, nº.3, p. 598 - 604, 2016

ISSN 1982-7679 (On-line)

Fortaleza, CE, INOVAGRI - http://www.inovagri.org.br

DOI: $10.7127 /$ rbai.v10n300345

Protocolo 345.16 - 13/08/2015 Aprovado em 05/06/2016

\title{
ÁGUA DISPONÍVEL E COBERTURA DO SOLO SOB O CRESCIMENTO INICIAL DO FEIJÃO-CAUPI CV. BRS PUJANTE
}

\author{
Tarso Moreno Alves de Souza ${ }^{1}$, Tássio Almeida Souza ${ }^{1}$, Lauter Silva Souto ${ }^{1}$, \\ Francisco Vanies da Silva Sá ${ }^{2 *}$, Emanoela Pereira de Paiva ${ }^{3}$, Evandro Franklin de \\ Mesquita $^{4}$ \\ RESUMO
}

Objetivou-se avaliar o efeito de níveis de água disponível no solo, com e sem cobertura morta sob o crescimento de plantas de feijão-caupi cv. BRS Pujante. O experimento foi realizado em casa de vegetação da Universidade Federal de Campina Grande, no município de Pombal-PB, no período de dezembro de 2014 a março de 2015. O delineamento experimental adotado foi o de blocos inteiramente casualizados. $\mathrm{O}$ arranjo dos tratamentos constituiu um fatorial $5 \times 2$, correspondente aos níveis de água disponível no solo (20; 40; 60; 80 e 100\%), com e sem cobertura morta, sendo quatro repetições, num total de 40 unidades experimentais. Aos 30 dias após a semeadura, as plantas foram caracterizadas quanto o crescimento, avaliando-se o diâmetro de caule, o número de folhas, a área foliar, a massa fresca e a massa seca das plantas. A redução da água disponível no solo afetou o crescimento e acúmulo de fitomassa das plantas de feijoeiro-caupi cv. BRS Pujante. O maior crescimento e acúmulo de fitomassa durante os primeiros 30 dias após a semeadura é atingido em níveis de água disponível de próximos a 68 a $72 \%$ da capacidade de campo. A cobertura do solo reduziu os efeitos do estresse hídrico sob as plantas de feijoeiro-caupi cv. BRS Pujante.

Palavras-chave: Vigna unguiculata, déficit hídrico, cobertura morta.

\section{AVAILABLE WATER AND LAND COVER IN THE INITIAL GROWTH OF COWPEA CV. BRS PUJANTE}

\footnotetext{
ABSTRACT

In order to study the effect of levels of available water in soil, with and without mulch under growth of cowpea plants cv. BRS Pujante. The experiment was conducted in metallic greenhouse (greenhouse), Federal University of Campina Grande, in the municipality of

*Autor correspondente

${ }^{1}$ Unidade Acadêmica de Ciências Agrárias, CCTA/UFCG, Caixa Postal 1770, CEP 58840-000, Pombal (PB); tarsomoreno.agro@gmail.com; tassiobuzu@hotmail.com; lauter@ccta.ufcg.edu.br;

${ }^{2}$ Departamento de Engenharia Agrícola, CTRN/UFCG, Caixa Postal 882, CEP 58.429-900, Campina Grande (PB); vanies-agronomia@hotmail.com;

${ }_{3}$ Departamento de Ciências Vegetais, UFERSA, Caixa Postal 137, CEP 59625-900, Mossoró (RN); emanuelappaiva@hotmail.com;

${ }^{4}$ Departamento de Agrárias e Exatas, UEPB, Sitio Cajueiro S/N, CEP 58844-000, Catolé do Rocha (PB); elmesquita4@uepb.edu.br.
} 
Pombal-PB, Brazil, from December 2014 to March 2015. The statistical design was completely randomized. The arrangement of the treatments constituted a factorial $5 \times 2$, corresponding to the levels of available water in the soil (20,40, 60, 80 and 100\%), with and without mulch, with four repetitions, totaling the 40 experimental units. At 30 days after sowing plants were characterized by growth, being determined: the stem diameter, number of leaves, leaf area, fresh and dry weight of plants. The reduction of available soil water affected the growth and biomass accumulation of cowpea plants cv. BRS Pujate. The increased growth and biomass accumulation during the first 30 days after sowing is achieved water levels available near 68 to $72 \%$ of field capacity. The soil cover reduced the effects of water stress under the cowpea plants cv. BRS Pujante.

Keywords: Vigna unguiculata, water deficit, mulch.

\section{INTRODUÇÃO}

O feijão-caupi (Vigna unguiculata (L.) Walp.) é uma dicotiledônea pertencente à família Fabaceae, no Brasil, é conhecido por nomes populares como feijão-de-corda e feijão macassar (FREIRE FILHO et al., 2011). A região Nordeste do país é a principal produtora, concentrando 1,2 milhão de hectares cultivadas com feijão-caupi, seguida pela região Norte com 55,8 mil hectares, com uma produtividade média de 366 kg.ha-1 ${ }^{-1}$ em função do baixo nível tecnológico empregado no cultivo (ANDRADE et al., 2010; FREIRE FILHO et al., 2011).

Dados de pesquisa afirmam que o feijãocaupi tem potencial genético para alcançar maiores produtividades quando em cultivo irrigado, haja vista que a disponibilidade de água é um dos fatores mais limitantes da produção de grãos do feijão-caupi em condições semiáridas, promovendo reduções na produtividade da cultura intensidade da duração ou intensidade do déficit hídrico. Neste contexto, a irrigação se torna uma prática necessária para melhor desenvoltura da cultura do feijão-caupi em regiões com problemas de disponibilidade de água (MOUSINHO et al., 2008; BLANCO et al., 2011; RAMOS et al., 2012).

Apesar do uso de sistemas de irrigação promover um fornecimento de água adequado no período mais crítico da cultura, para que esta se adeque as condições de déficit hídrico, é necessário a incorporação de outras estratégias, como o uso da cobertura do solo, que reduz a evapotranspiração e aumenta a eficiência de menores lâminas de irrigação no suprimento hídrico da cultura (FERREIRA et al., 2015).

Blanco et al. (2011) avaliaram diferentes lâminas de irrigação sob os componentes de produção do feijão-caupi consorciado com o milho e verificaram que o feijão-caupi respondeu linearmente à irrigação, com a máxima produtividade obtida sob a lâmina de $640 \mathrm{~mm}$. Porém, pouco se sabe sobre a influência do manejo ótimo da água de irrigação sob as características de crescimento inicial da cultura do feijão-caupi, principalmente de cultivares recentemente incorporadas ao medrado, a exemplo da cultivar BRS Pujante (SANTOS et al., 2007).

Neste cenário, o presente trabalho objetivou avaliar o efeito de níveis de água disponível no solo com e sem cobertura morta sob o crescimento de plantas de feijão-caupi cv. BRS Pujante.

\section{MATERIAL E MÉTODOS}

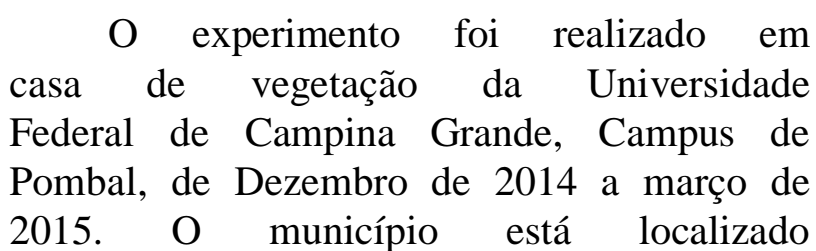
geograficamente na longitude $37^{\circ} 48^{\prime} 06^{\prime}$ ' W e latitude - $06^{\circ} 46^{\prime} 13^{\prime}$ ' $\mathrm{S}$, com altitude média de 184 metros.

O delineamento experimental adotado foi o de blocos inteiramente casualizados. 
O arranjo dos tratamentos constituiu um fatorial 5 x 2, correspondente aos níveis de água disponível $(\mathrm{AD})$ de $20 ; 40 ; 60 ; 80$ e $100 \%$ (testemunha), mantido após as irrigações do solo, em função da cobertura morta (CC) e sem cobertura (SC), com 10 tratamentos e quatro repetições, totalizando 40 unidades experimentais.

$\mathrm{O}$ ensaio foi realizado em unidades experimentais compostas de vasos com capacidade de $12 \mathrm{dm}^{3}$, preenchidos com solo classificado como Neossolo Flúvico (SANTOS et al., 2013) (Tabela 1). A adubação de fundação foi realizada com base na análise de solo e no boletim técnico de recomendação de adubação para estado de Pernambuco (CAVALCANTI et al., 2008) e consistiu-se na aplicação de 60 $\mathrm{kg} \mathrm{ha}^{-1}$ de $\mathrm{P}_{2} \mathrm{O}_{5}$ e $40 \mathrm{~kg} \mathrm{ha}^{-1}$ de $\mathrm{K}_{2} \mathrm{O}$, nas formas de superfosfato simples e cloreto de potássio, respectivamente. Vinte dias após a semeadura, fez-se aplicação de $20 \mathrm{~kg}$ $\mathrm{ha}^{-1}$ de $\mathrm{N}$ em cobertura na forma de ureia.

Tabela 1. Analise química e de fertilidade do solo utilizado no experimento.

\begin{tabular}{|c|c|c|c|c|c|c|c|c|c|}
\hline $\mathrm{pH}$ & & $\mathrm{K}^{+}$ & $\mathrm{Na}^{+}$ & $\mathrm{Ca}^{+2}$ & $\mathrm{Mg}^{+2}$ & $\begin{array}{l}\mathrm{H}^{+}+ \\
\mathrm{Al}^{+3}\end{array}$ & CTC & \multirow{2}{*}{$\begin{array}{c}\mathrm{MO} \\
\mathrm{g} \mathrm{Kg}^{-1}\end{array}$} & \multirow{2}{*}{$\begin{array}{c}\text { PST } \\
\%\end{array}$} \\
\hline $\mathrm{H}_{2} \mathrm{O}$ & $\mathrm{mg} \mathrm{dm} \mathrm{dm}^{-3}$ & -... & & 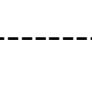 & $\mathrm{nol}_{\mathrm{c}}$ & & 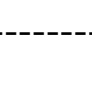 & & \\
\hline 8,2 & 177 & 0,41 & 0,65 & 3,9 & 1,5 & 0,0 & 6,5 & 31,95 & 10 \\
\hline
\end{tabular}

$\mathrm{P}, \mathrm{K}$, Na: Extrator Mehlich 1; Al, Ca, Mg: Extrator KCL 1M; $\mathrm{SB}=\mathrm{Ca}^{+2}+\mathrm{Mg}^{+2}+\mathrm{K}^{+}+\mathrm{Na}^{+} ; \mathrm{H}+\mathrm{Al}$ : Extrator Acetato de Cálcio 0,5 M, pH 7,0; $\mathrm{CTC}=\mathrm{SB}+\mathrm{H}^{+}+\mathrm{Al}^{+3}$; M.O.: Digestão Úmida Walkley-Black; PST= Percentagem de Sódio Trocável.

Foram semeadas quatro sementes de feijão-caupi da cultivar BRS Pujante em cada vaso à uma profundidade de $2 \mathrm{~cm}$, onde a emergência das plântulas se estabilizou no quinto dia após a semeadura. O desbaste foi realizado 15 dias após a semeadura (DAS), mantendo-se a planta mais vigorosa. Após a semeadura realizou-se a cobertura do solo, utilizando-se de folhas de Pau Ferro (Caesalpinia leiostachya (Benth.) Ducke) como cobertura morta na superfície do solo, na quantidade de $40 \mathrm{~g}$ de folhas secas por vaso, resultando em uma camada de 3 a $5 \mathrm{~cm}$. Os tratos culturais foram realizados para manter a cultura livre de plantas invasoras, doenças e pragas durante a condução do experimento.

As irrigações foram realizadas diariamente com um volume uniforme de água $\left(\mathrm{Ce}_{\mathrm{a}}=0,3 \mathrm{dS} \mathrm{m}^{-1}\right)$, em função da evapotranspiração média no tratamento testemunha, obtida por pesagem. O volume aplicado (Va) por recipiente foi obtido pela diferença entre a média do peso dos recipientes em condição de máxima retenção de água $\left(\mathrm{P}_{\mathrm{cc}}\right)$, o qual foi determinado saturando-se os recipientes com água e submetendo-os à drenagem; quando o volume drenado estabilizou os recipientes foram pesados, obtendo-se com isso, o valor do $\mathrm{P}_{\mathrm{cc}}$, ou seja o peso dos recipientes na máxima capacidade de retenção de água; e o peso médio dos recipientes na condição atual $\left(\mathrm{P}_{\mathrm{a}}\right)$, dividido pelo número de recipientes $(\mathrm{n})$, como indicado na equação 1:

$$
\mathrm{Va}=\frac{\mathrm{Pcc}-\mathrm{Pa}}{\mathrm{n}} \quad \text { Eq. } 1
$$

Aos 30 dias após a semeadura, as planas de feijão-caupi foram avaliadas quanto ao diâmetro do caule com auxilio de um paquímetro digital; quanto ao número de folhas por meio da contagem das folhas maduras e posteriormente as mesmas foram coletadas para a determinação da área foliar obtida através de um integrador de área foliar $\left(\mathrm{cm}^{2}\right)$ de bancada LICOR, modelo 3100C. Em seguida, foram acondicionadas em sacos de papel e submetidas à secagem em estufa com circulação forçada de ar à $65^{\circ} \mathrm{C}$ até atingir peso constante. Após a secagem, foi determinada a massa de matéria seca total (folhas e caule + pecíolo) em balança analítica. 
Os efeitos dos níveis de água disponível $(\mathrm{AD})$ e da cobertura (COB) e da interação $\mathrm{AD}$ Versus $C O B$ foram avaliados estatisticamente através da análise de variância. Para as variáveis em que os níveis de água disponível, os níveis de cobertura ou a interação $\mathrm{AD} x$ $\mathrm{COB}$ foram significativas de acordo com 0 teste F, efetuou-se análise de regressão. Nesta análise foram testados os modelos linear e quadrático, sendo que para expressar o comportamento de cada variável foi selecionado o modelo que apresentou significância a $5 \%$ de probabilidade $(\mathrm{p}<0,05)$ e o maior coeficiente de correlação para os dados obtidos. Para isso, utilizou-se do software estatístico SISVAR (FERREIRA, 2011).

\section{RESULTADOS E DISCUSSÃO}

Houve influência significativa $(\mathrm{p}<0,05)$ da interação entre os níveis de água disponível no solo versus as condições de cobertura do solo para as variáveis: diâmetro de caule, número de folhas, área foliar, massa fresca e massa seca do feijão-caupi cv. BRS Pujante aos 30 dias após a semeadura (Figuras 1 e 2).

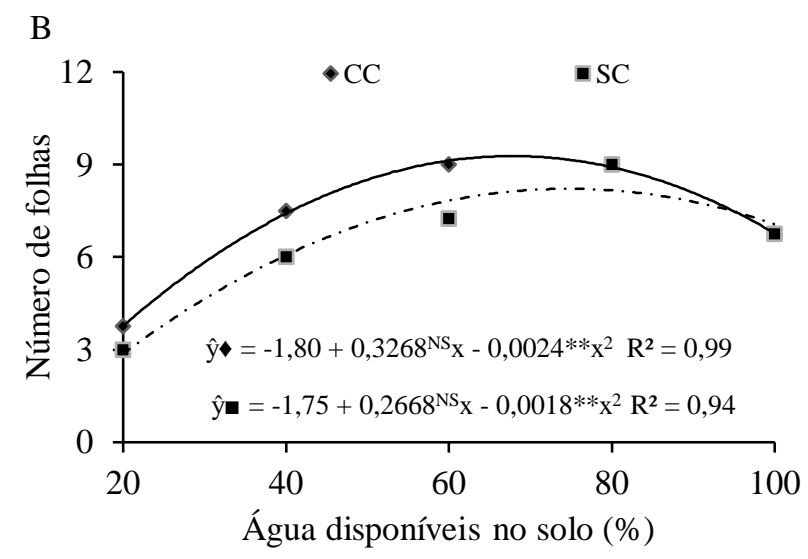

A

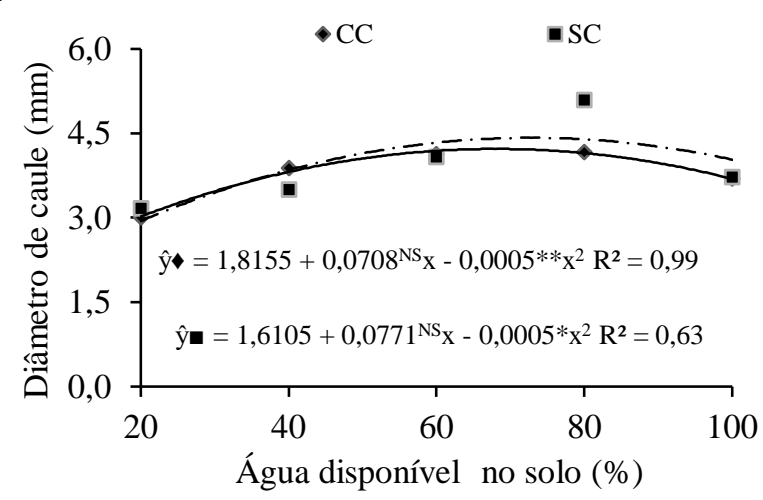

C

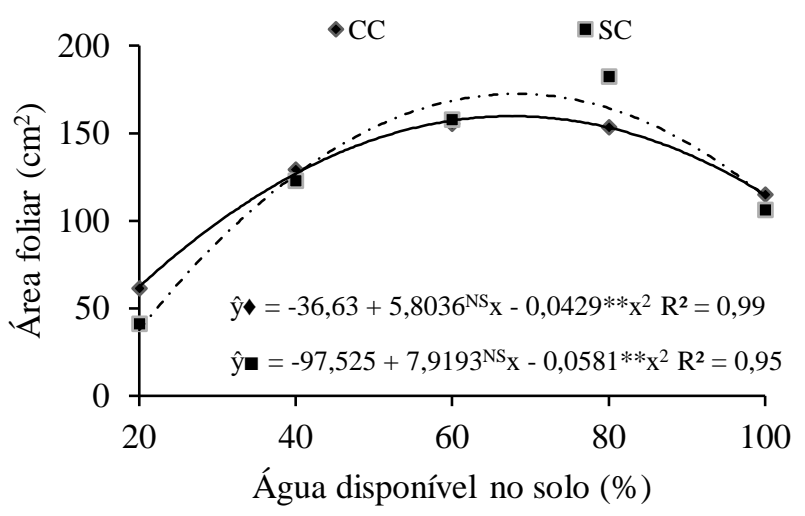

Figura 1. Diâmetro de caule (A), número de folhas (B) e área Foliar (C) de plantas de feijão-caupi cv. BRS Pujante aos 30 dias após a semeadura, cultivado sob diferentes níveis de água disponível no solo, com (CC) e sem cobertura (SC).

Para o diâmetro do caule foi possível observar diferença significativa para os diferentes níveis de água disponível no solo através do ajuste de regressão quadrática, com os valores aumentando nos tratamentos até o nível de 71 e $77 \%$ de $\mathrm{AD}$ para os solos com e sem cobertura morta, respectivamente (Figura 1 A). Notou-se efeitos extremamente negativos, sendo crítico para os níveis de 20 e $40 \%$ AD, 
confirmando os resultados obtidos por Leite et al. (1999); Nascimento et al. (2004) e Freitas et al., (2014), os quais constataram efeito significativo de déficit hídrico na fase vegetativa do caupi na redução dos componentes de crescimento.

Verificou-se ainda, que as plantas cultivadas no solo sem cobertura obtiveram maiores diâmetros do caule, no entanto, estas plantas necessitaram de maiores níveis de água em relação às cultivadas no solo com cobertura (Figura $1 \mathrm{~A}$ ). Este fato pode estar relacionado à intensificação do crescimento secundário, de modo a elevar eficiência dos vasos condutores (Xilema), os quais são responsáveis por conduzir água das raízes às folhas, que por sua vez promovem o advento da transpiração responsável por regular a atividade térmica no interior da planta (TAIZ; ZAIGER, 2013).

Além disso, pôde-se constatar que os maiores número de folhas foram obtidos sob o nível de 68 e 74\% de AD no solo, obtendo 9,3 folhas por planta no tratamento com cobertura morta e 8,1 folhas por planta no tratamento sem cobertura morta, respectivamente (Figura $1 \mathrm{~B}$ ). No solo com cobertura foi observado um maior número de folhas com um menor requerimento de água em relação ao solo sem cobertura, isso denota a importação da cobertura morta para o cultivo do feijão-caupi em regiões semiáridas, tendo vistas as folhas são os centros de produção de fotoassimilados (órgão fontes), e que o resto da planta (órgãos drenos) dependem da exploração dos produtos produzidos nas folhas, assim, pode-se afirmar que a redução do número de folhas afeta diretamente o crescimento e produção das plantas (LEITE et al., 1999). Segundo Larcher (2006), a deficiência de água promove a perda progressiva da turgescência protoplasmática e aumenta a concentração de solutos na planta, promovendo déficits funcionais e danificando as estruturas protoplasmáticas.

Na Figura 1, é possível observer o comportamento quadrático da área foliar (AF) em função do incremento do nível de água disponível no solo. Os maiores valores foram verificados quando se mantiveram $68 \%$ da água disponível no solo com e sem cobertura. No entanto, as plantas cultivadas no solo sem cobertura obtiveram maiores incrementos com o aumento da lâmina de irrigação, fato que pode estar relacionado à maior intensidade do estresse hídrico sob essas plantas, de modo a ampliar as respostas de crescimento em função da maior disponibilidade de água.

Resultados semelhantes aos observados nesta pesquisa foram constatados por Bastos et al. (2012) que, ao avaliarem diferentes regimes hídricos na cultura do feijão-caupi, concluíram que o aumento na AF tem uma correlação positiva com o rendimento de grãos. Para Correia e Nogueira (2004); Silva et al. (2013) e Freitas et al. (2014), a redução na área foliar total de plantas sob déficit hídrico pode ser atribuída à estratégia de sobrevivência ao diminuir a área disponível para o processo de transpiração. De um modo geral, a área foliar se apresenta como um importante parâmetro na determinação da capacidade fotossintética das culturas (NASCIMENTO, 2009). Segundo Larcher (2006), a redução da perda de água devido ao decréscimo da superfície de transpiração da planta é uma das medidas comportamentais de resistência ao déficit hídrico. No presente estudo, este comportamento também foi constatado, principalmente quando as plantas da cv. BRS Pujante foram submetidas aos menores níveis de água disponível no solo (20 e 40\%).

Para a MF e MS observou-se comportamento quadrático do acúmulo de fitomassa das plantas de feijão-caupi em função dos níveis de água disponível no solo, obtendo acréscimos no acúmulo de fitomassa até os níveis de $\mathrm{AD}$ de 69 e 68\%, obtendo-se 6,1 e 6,6 g de MF, e até os níveis de AD de 68 e $72 \%$, com acúmulo de massa seca de 0,72 e $0,91 \mathrm{~g}$ nos solos com e sem cobertura morta, respectivamente (Figura 2 A e B). Este resultado está de acordo com o que Nascimento et al. (2004); Medes et al. (2007) e Freitas et al. (2014), que verificaram um acréscimo significativo no acúmulo de fitomassa das 
plantas à medida que se aumenta a disponibilidade de água para planta.

A

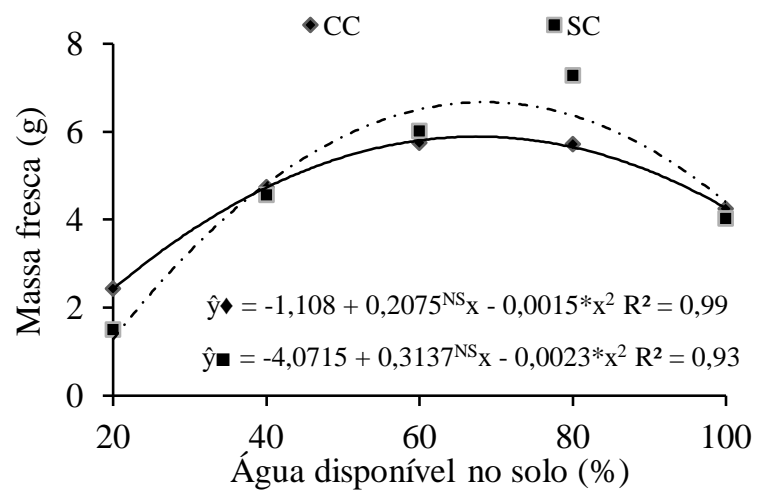

B

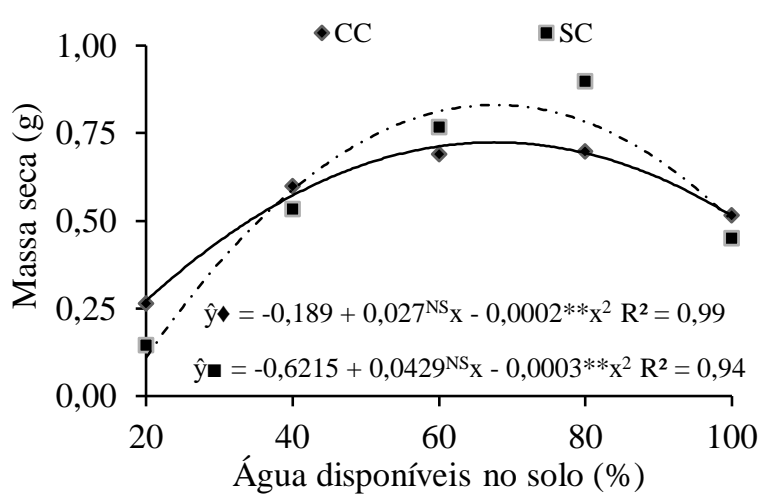

Figura 2. Massa fresca (A) e massa seca (B) de plantas de feijão-caupi cv. BRS Pujante aos 30 dias após a semeadura, cultivado sob diferentes níveis de água disponível no solo, com (CC) e sem cobertura (SC).

Nos níveis de água próximos a 100\% da capacidade de campo ocorreram decréscimos no acúmulo de fitomassa, possivelmente devido à redução da aeração do solo, haja vista a menor necessidade de água pela cultura nas fases iniciais de crescimento, ocasionando estresse hipóxico nas plantas sob solos com a capacidade máxima de retenção de água. Esse fenômeno pode ter ocorrido com maior intensidade no solo com cobertura morta, de modo que essa prática reduz as perdas de água por evaporação, deixando o solo úmido por mais tempo quando comparado ao solo sem cobertura (FERREIRA et al., 2015). Dessa forma para a fase de crescimento do feijoeirocaupi cv. BRS Pujante são indicadas lâminas de água que condicione uma disponibilidade de água de 68 a 72\% da capacidade de campo.

\section{CONCLUSÕES}

A redução da água disponível no solo afetou o crescimento e acúmulo de fitomassa das plantas de feijoeiro-caupi cv. BRS Pujante.

O maior crescimento e acúmulo de fitomassa durante os primeiros 30 dias após a semeadura é atingido em níveis de água disponível de próximos a 68 a $72 \%$ da capacidade de campo.

A cobertura do solo reduziu os efeitos do estresse hídrico sob as plantas de feijoeirocaupi cv. BRS Pujante.

\section{REFERÊNCIAS}

ANDRADE, F. N.; ROCHA, M. de M.; GOMES, R. L. F.; FREIRE FILHO, F. R.; RAMOS, S. R. R. Estimativas de parâmetros genéticos em genótipos de feijão-caupi avaliados para feijão fresco. Revista Ciência Agronômica, v. 41, n. 2, p. 253-258, 2010.

BASTOS, E. A.; RAMOS, H. M. M.; ANDRADE JÚNIOR, A. S.; NASCIMENTO, F. N.; CARDOSO, J. M. Parâmetros fisiológicos e produtividade de grãos verdes do feijão-caupi sob déficit hídrico. Water Resources and Irrigation Management, v. 1, n. 1, p. 31-37, 2012.

BLANCO, F. F.; CARDOSO, M. J.; FREIRE FILHO, F. R.; VELOSO, M. E. C.; NOGUEIRA, C. C. P.; DIAS, N. S. Milho verde e feijao-caupi cultivados em consórcio sob diferentes lâminas de irrigação e doses de fósforo. Pesquisa Agropecuária Brasileira, v. 46, n. 5, p. 524-530, 2011.

CAVALCANTI, F. J. et al. Recomendações de adubação para o Estado de Pernambuco. $2^{a}$ Aproximação. Recife - Instituto Agronômico de Pernambuco - IPA, 2008. 212p. Il.

FERREIRA, D. F. Sisvar: a computer statistical analysis system. Ciência Agrotecnologia, v. 35, n. 6, p. 1039-1042, 2011. 
FERREIRA, N. M.; MESQUITA, E. F.; SÁ, F. V. S.; BERTINO, A. M. P.; PAIVA, E. P.; FARIAS, S. A. R. Crescimento e produção da mamoneira BRS Paraguaçu sob irrigação, cobertura do solo e adubação orgânica. Revista Brasileira de Engenharia Agrícola e Ambiental, v. 19, n. 9, p. 857-864, 2015.

FREIRE FILHO, R. R.; RIBEIRO, V. Q.; ROCHA, M. M.; SILVA, K. J. D.; ROCHA, M. S.; RODRIGUES, E. V. Feijão-caupi no Brasil: produção, melhoramento genético, avanços e desafios. Teresina: EMBRAPA Meio-Norte, 2011. 84 p.

FREITAS, R. M. O.; DOMBROSKI, J. L. D.; FREITAS, F. C. L.; NOGUEIRA, N.W.; PINTO, J. R. S. Crescimento de feijão-caupi sob efeito de veranico nos sistemas de plantio direto e convencional. Bioscience Journal, v. 30, n. 2, p. 393-401, 2014.

LARCHER, W. Ecofisiologia vegetal. São Carlos: RIMA Artes e Textos, 2006. 532p.

LEITE, M.L.; RODRIGUES, J.D.; MISCHAN, M.M.; VIRGENS FILHO, J.S. Efeitos do déficit hídrico sobre a cultura do caupi [Vigna unguiculata (L.) Walp], cV. EMAPA-821. II Análise de Crescimento. Revista de Agricultura, v. 74, n. 3, p.351-370, 1999.

MENDES, R. M. S.; TÁVORA, F. J. A. F.; PITOMBEIRA, J. B.; NOGUEIRA, R. J. M. C. Relações fontedreno em feijão-de-corda submetido à deficiência hídrica. Revista Ciência Agronômica, v. 38, n. 1, p. 95-103, 2007.

MOUSINHO, F. E. P.; ANDRADE JÚNIOR, A. S.; FRIZZONE, J. A. Viabilidade econômica do cultivo irrigado do feijão-caupi no Estado do Piauí. Acta Scientiarum. Agronomy, v. 30, n. 1, p. 139-145, 2008.
NASCIMENTO, J.T.; PEDROSA, M. B.; AVARES SOBRINHO, J. Efeito da variação de níveis de água disponível no solo sobre o crescimento e produção de feijão caupi, vagens e grãos verdes. Horticultura Brasileira, v. 22, n. 2, p.174-177, 2004.

NASCIMENTO, S. P. do. Efeito do déficit hídrico em feijão-caupi para identificação de genótipos com tolerância à seca. 2009. $109 \mathrm{f}$. Dissertação (Mestrado em Agronomia) Universidade Federal do Piauí.

RAMOS, H. M. M.; BASTOS, E. A.; ANDRADE JÚNIOR, A. S.; MAROUELLI, W. A.; Estratégias ótimas de irrigação do feijao-caupi para produção de grãos verdes. Pesquisa Agropecuária Brasileira, v. 47, n. 4, p. 576-583, 2012.

SANTOS, C. A. F. Feijão-caupi BRS Pujante: cultivar para áreas irrigadas e de sequeiro do vale do São Francisco. Petrolina: Embrapa Semi-Árido, 2007. 1 Folder.

SANTOS, H. G.; JACOMINE, P. K. T.; ANJOS, L. H. C.; OLIVEIRA, V. A.; LUMBRERAS, J. F.; COELHO, M. R.; ALMEIDA, J. A.; CUNHA, T. J. F.; OLIVEIRA, J. B. Sistema Brasileiro de Classificação de Solos. 3 ed. rev. ampl. Brasília, DF : Embrapa, 2013. 353 p.

SILVA, W. C.; PEREIRA, J. S.; TELES, V. O.; CAMARA, F. T. Efeito da disponibilidade de água na germinação e no desenvolvimento inicial de plântulas de feijão-caupi. Enciclopédia Biosfera, v. 9, n. 16; p. 29842993, 2013.

TAIZ, L.; ZEIGER, E. Fisiologia vegetal. 5.ed. Porto Alegre: Artmed, 2013. 918p. 